\title{
Addressing Inequality: Framing Social Protection in National Development Strategies
}

\author{
Kate Carroll
}

\begin{abstract}
It is important to address different inequalities and one way to achieve this is through social protection as a mechanism for redistribution. Achieving social justice and a reduction in inequalities through social protection will also require other policies to be in place. This article suggests that social protection will be most effective at reducing inequalities if it is integrated in a coherent national development strategy (NDS), which provides a framework for policy formulation and linkages, and if policies are rooted in solid analysis to enable them to target specific inequalities. It also argues that NDSs need to be formulated so that they are based on alternative visions of development that give voice to various groups, notably the excluded. ActionAid's NDS project is provided as an example of how to reduce inequalities and advance redistributive and transformative social protection.
\end{abstract}

\section{What are inequalities and why is it important to understand them? \\ Inequality is commonly associated with disparities in income. This is partly because the most commonly used measurement, the Gini coefficient, maps out income distribution. However, the Gini coefficient is based on net income, and does not reflect differences in wealth and assets. It only considers income produced from work and fails to consider wealth differences related to land, property, industry or capital profits. Most conceptually important, it does not account for other sources of inequalities.}

There are multiple types of inequality, which compound and reinforce each other. These include inequalities of gender, class, caste, geography, ethnicity and race. When this article refers to 'inequality', it means 'inequalities', since its constituent parts are difficult to separate. Inequality is primarily the outcome of negative power dynamics. Power operates in all areas of our lives and is embedded within all institutions: family, communities, society and the state. Power dynamics are inevitable, and need to be checked since they are usually asymmetrical: one person or institution's power can unjustly restrict or undermine another's potential. This is especially the case in a rigid hierarchical structure, and this is where power can have the most negative impact. One key problem with inequality is that those who suffer are the already vulnerable. Hence, inequality exacerbates and intensifies existing injustices and power imbalances.

\section{Why is inequality a problem?}

Inequality can be associated with a violation of human rights. The Universal Declaration of Human Rights (UDHR) states: 'All human beings are born free and equal in dignity and rights'. Of course, this is an ideal scenario: we are in fact born into contexts which are more or less unequal. In addition, some perceived inequalities are the result of choice. For example, if a person chooses to work part-time, they will earn less than their full-time colleagues. Their inequality in income is not the result of a violation of human rights. Values of equality and dignity nevertheless underlie rights such as the right to take part in public affairs, to social security, to an adequate standard of living and to not be discriminated against. Poor men and women who suffer increasingly from persistent social, political and economic inequalities, are most prone to shocks, and are unable to realise their rights. This is because 
their voices are unrecognised. In the case of women, inequality is exacerbated: women are more likely to have their rights denied, such as the right to education, to health services or to bodily integrity. Because of inequalities of power, women are less able to claim their rights.

One reason that people are unable to escape inequality is because inequality skews access to power and decision-making, assets, opportunities and government support. This creates what Townsend (2002) calls 'social polarisation', which further exacerbates inequality and is transmitted from one generation to the other. For example, there are few women in powerful positions in either the public or the private sphere, so that gender inequality is institutionalised. While those women in power may not necessarily promote gender equity, the likelihood of women's perspectives to be recognised, heard or acted upon is nevertheless reduced.

Other reasons for why inequality is a problem are identified by Claire Melamed in a (currently unpublished) 2011 paper for ActionAid:

1 People being forced to accept substantially lower living standards than others is an injustice (the moral case).

2 Inequality can make poverty permanent for some groups.

3 Less inequality means better politics as more people's voices are heard in the debate.

4 Growth accompanied by rising inequality leads to slower poverty reduction than growth where inequality stays the same or falls.

5 A more equitable starting point improves the link between growth and poverty reduction as countries develop.

6 High inequality can harm economic growth.

7 Lower inequality can promote faster economic growth.

8 Less inequality means more stable growth.

9 Increasingly, poverty will be about inequality within countries as well as about absolute levels of resources. (How are we distributing resources within middle-income countries, as well as between rich and poor countries?)

10 If growth is to be limited by environmental constraints, reducing inequality becomes an ever more important means of reducing poverty.

The opportunity is that because some inequality is predictable, it can be avoided. Social protection is one policy option for addressing inequality. Rather than addressing the symptoms of inequality through safety nets, transformative social protection policies would be designed to address the causes.

\section{How might social protection reduce inequality?}

Social protection interventions can reduce different inequalities, although they are not always crafted to do so. If the roots of inequality lie in power and systems that perpetuate power, then the way to achieve equitable social justice is to tackle the systems of power. One way this can be achieved is through redistribution - of incomes, assets, access to social services and access to power and decision-making.

Redistributive policies should not only transfer resources but should also aim to transfer power. The transfer of power, in the presence of other rights such as to health, education and food, is what makes policies achieve their transformational potential and enables people to move out of their context of vulnerability in a more sustainable manner. For example, evidence from health, education and social protection analysis in ActionAid cross-country studies suggests that redistributive social policies policies that transfer power as well as income from the rich and powerful to the powerless have the potential to be transformative and reduce different types of inequality and poverty.

Brazil has tackled historical inequalities through the introduction of four types of social protection interventions, which might be considered as a transformative approach. These are:

income transfer programmes such as Bolsa Familia;

- an asset-related Programa Nacional de Fortalecimiento da Agricultura Familiar (PRONAF) - a programme to strengthen family agriculture; 
- progressive social service policies such as the Family Health Programme;

- basic human rights to health, education and employment.

Since the introduction of these policies, some forms of inequality have fallen dramatically. For example, there has been a faster rise in the incomes of the poorest, who also have more opportunities to access social services. However, other forms of inequality are improving more slowly and still need to be addressed. This applies in particular to the power relations between women and men, which have not been specifically addressed in any of Brazil's approaches.

Thus, one can argue that to ensure transformation in power, social protection has to be part of a social policy package, including free quality education, free universal health care and fundamental labour rights. In addition, it must be accompanied by a wide framework of complementary civil and political, social and economic rights. A rights and inequality analysis will help to identify the most appropriate combination of interventions and help avoid issues being missed. For example, with regard to gender equality and women's rights, few policy packages look at the unequal power relationship between men and women and consider which social protection interventions might be useful to transform this.

\section{Challenges with influencing to ensure that social protection reduces inequality}

There are a number of challenges with doing influencing work which ensures that the social protection agenda better reduces inequality. First, while some civil society groups - such as South Africa's Basic Income Grant (BIG) campaign and various labour movements in Asia - do include human rights, in general insufficient attention is paid to this dimension. Second, the stakeholders who might push the human rights and inequality agenda are not a cohesive group. Rather than join forces, civil society lobbying has tended to operate in silos, with each organisation pushing their own agenda, for example around children, the aged or people living with HIV/AIDS. Third, different regions have very different priorities. As a result, programme designs often remain without a transformative approach; accountability of governments to citizens on social protection issues is weak and there are few opportunities to link across regions.

One way to address these challenges is through working in coalitions. Inequalities are faced and rooted in all sectors, and building a cross-sectoral response could create a more transformative approach. A notable example of civil society coming together collectively is the Africa Platform for Social Protection. ${ }^{1}$

A fourth challenge in social protection advocacy is that it tends to go in one of two, equally challenging, directions. It sometimes tries to cover all issues - all vulnerabilities, all socioeconomic rights and all civil and political rights - which makes it a very big and unwieldy subject. Alternatively, it is conceived very narrowly - only looking at social transfers, which means there is less potential to be transformative. A fifth challenge is that social protection issues are rarely addressed by just one government institution. Influencing government involves negotiating with different ministries and multiple donors, all with different agendas. This is no less a problem within organisations. For example, as an influencing agency, ActionAid needs to address the cross-cutting nature of social protection by involving stakeholders from each of its programmatic areas: women's rights, education, health, food, human security and governance.

Sixth, mobilising communities or constituencies on social protection is challenging at a local level when there is little awareness of it being a right. Mobilisation tends to be more common at national level and takes place when provisions are taken away or are being reformed - the recent demonstrations over pension reform in France is one example. Moving forward, one approach could be to identify one contextspecific social protection priority, perhaps a sector where inequality is greatest, and to influence on that issue within the broader social protection floor framework. For example, Lesotho focused on cash transfers as its first priority within the 'social protection floor' because analysis suggested that, since HIV/AIDS had left a missing middle generation in the demographic, with many families comprising grandparents caring for their grandchildren, a pension would be the best way to ensure that money reached the most vulnerable. 
Women's specific interests and voices are often missing from the design of programmes, which means they are less likely to address inequality between men and women. While women are often part of discussions around social protection, their role is instrumentalised. The narrative is that if cash transfers are disbursed to women, there is a greater likelihood of 'productive' outcomes. The fact that many social protection mechanisms have health or education conditions, or are given only to women, leads to the misconception that they incorporate a women's rights perspective. Mexico's Oportunidades programme is an example of this: a cash transfer is given to the female household head and is conditional on the children going to school and attending health clinics. The state thereby recognises that it is women who do most of the unpaid care work, which is a positive step; however, these types of social protection schemes ultimately serve to reinforce women's disproportionate responsibility for care. They also fail to consider the reality for many women living in poverty, who do engage in other work than care responsibilities. Making cash transfers conditional on women proving that their children are at school and receiving health care creates bureaucratic processes which add to women's already burdensome workload. Indeed, by connecting women with the reproductive and care sectors only, there is a danger that policymakers further institutionalise women's role as carers and ignores their role as wage-earners. While there is no doubt that women do want to ensure their children have good health and education, this should not be packaged only as a women's rights issue, nor should there be an assumption that, just because an issue may concern women, the process will be empowering for women. Empowerment will only take place if it is clearly part of programming plans and if there is voice (Razavi 2009).

Another challenge is that there need to be explicit links between social protection policies and wider social and economic processes. Social protection should not replace universal social policies around health and education. For example, having a pension may well enable an older woman to bring her grandchild to a health clinic, but it must not be used to justify reducing spending on universal health care or introducing user fees (Razavi 2009). Synergy between social and economic policy is important. For example, a feminist perspective to social protection would support women and gender equality throughout their lives: it would recognise care roles, whoever takes them, and support would go further than the introduction of health and education policies - it would enable women to transform their livelihoods and lives. This might involve looking at women's labour rights and gender

discrimination in the workplace. Women tend to engage in the informal sector - partly the result of having to balance care work in the home with employment. But within the informal sector, women are even more likely to be less well paid and to engage in more risky occupations than their male counterparts. Analysis would thus have to look into how social protection mechanisms could support informal as well as formal sector workers. This would have an impact on wider transformation: empowerment for a group of women rather than one woman. Some organisations have been set up to ensure this. One notable success is the Self-Employed Women's Association (SEWA). ${ }^{2}$

A final challenge lies in terminology. The term social protection is commonly used, but is understood differently by different donors and governments, thus necessitating documents to include lengthy definitions (Grosh et al. 2008). Organisations that wish to emphasise transformation and reduction of inequality find themselves limited by the association of social protection with only cash transfers. However, attempts to adopt alternative terminologies have all come across their own challenges. For example, the word 'welfare' has strongly negative political and dependency connotations in several countries.

The above issues suggest that it is difficult, in the social protection domain, to influence in addressing inequality. ActionAid's National Development Strategy (NDS) project, outlined below, attempts to address this.

\section{Integrating social protection in national development strategies (NDS): a key way of tackling inequality?}

An NDS is a vision, a strategy and a plan of action to manage a country's economic and social development. ${ }^{3}$ Ideally, such plans integrate policies around a human development and social justice vision, mapping out resources and budget priorities. NDSs function to different extents in different countries. Integrating inequality- 
reducing mechanisms, such as social protection within a country's NDS can be a key way to achieving social justice. This is because the roots of inequality are in the structures of society, within families, communities and government institutions. Creating policy change to address inequality within the country's overall strategy, through its plans, budgets and strategies can be a step leading to changes throughout the system. An example of an NDS is Nigeria's 12-year strategy - Vision 2020, which aims to place the nation among the world's 20 largest economies. Influencing this NDS, challenging its approach and aim and suggesting an alternative vision is a strategic way of influencing change.

The NDS provides an opportunity to create synergy across increasingly fragmented sectors to address inequalities. Working on a single national framework facilitates essential engagement. For example, a strategy to support women and to recognise their unpaid care work involves linking labour and education ministries. Cash transfers, accompanied by fundamental labour rights, could mean that women have more choice about how they use their time. This makes it easier for women to engage in paid work and earn a decent wage. It may also allow women to have more leisure time. With greater access to their own income, women may then have greater decisionmaking power in household budgets. A potential knock-on impact might be that more girls have the opportunity to go to school, because they are not required to stay at home to do housework and take care of siblings while their parents work. In order for this positive synergy to work, there needs to be a relationship between ministries, and this can be enhanced by the NDS framework.

Civil society tends to focus influence on fiscal expenditure. Through the NDS framework, civil society can influence fiscal revenue-raising. How revenue is raised to fund a policy is important to ensure that the policy is truly redistributive. Civil society has most potential to influence tax policy, by gathering evidence of the impact of progressive and regressive taxes and tracking tax raise and spend. The process of developing an NDS often includes feedback mechanisms which can create linkages between citizens and the state to ensure that rights are enjoyed and power shifts, as opposed to nominal legal changes, which are not enforced. This means that - in theory - it is more likely that rights are enjoyed.
While there are many opportunities to influence within the NDS framework, there is also a number of challenges with countries' current NDSs that mean it is more challenging to integrate redistributive and inequality-reducing mechanisms, such as social protection. A central challenge is that, while an NDS is proactively intended to be nationally led, in contrast to poverty reduction strategy papers (IMF 2011), which were perceived to be donor-led, they still need to be financed, and many are aimed at attracting funding from multilateral institutions and foreign direct investment (FDI). Financing, whether in the form of aid, private capital, borrowing or other investment is usually conditional. In order to attract capital, a country's NDS will tend to be based on market-oriented thinking and will be outwardly focused, rather than redistributive and citizen-led, and it is harder to fit social protection into such a model.

\section{What would the agenda on social protection to reduce inequalities look like within an NDS framework?}

In order to integrate redistributive and inequality-reducing mechanisms, it may be necessary to campaign for an 'alternative' NDS rather than accepting the current NDS. ActionAid's NDS project attempts to achieve this. Using a combination of local programming, country research, coalition building, advocacy and lobbying, ActionAid aims to influence governments to adopt an NDS that recognises the social and economic rights of all citizens and lays out a practical vision for citizen-led development, founded on the principles of: (1) redistribution of wealth for social justice and the reduction of inequality; (2) self-reliant growth, which is internally driven rather than reliant only on external markets; (3) ecological justice; and (4) women's rights, through recognition of the care economy. ${ }^{4}$

In order to build the policy space for discussions around an alternative NDS, it is important to think about propositional alternatives, and to have an agreed vision of redistributive social protection. One option is to build interest around the 'social minimum'; a concept that has multiple roots, but whose latest conception is the UN 'social protection floor' (UN, ILO, WHO 2010). This consists of two elements, transfers and basic rights provision, and allows a staged process to achieve a full social protection 
package. It is transformative and likely to reduce inequality because it links cash transfers to a broader rights framework and seeks to deliver in the long term. ActionAid's vision builds on this, with the aim that countries adopt appropriate universal transformative and redistributive social protection systems, outlined as part of their national development strategy, aiming to achieve social justice and reduce multiple inequalities such as between men and women. Systems would be based on a social minimum, namely the UN social floor, which consists of two elements; transfers and basic rights provision. Civil society and rightsholders would play a key part in monitoring and holding governments to account on promises.

Alternative NDSs could address a greater range of inequalities if they are representative of multiple views. Different interest groups should be brought into the proceedings, including and going beyond civil society movements, trades unions, farmers' movements, representatives of the informal economy, feminist organisations, faith-based groups and others.

Regarding gender equality and women's rights, alternative NDSs could address issues around the care economy and informal paid work. ActionAid's programming on unpaid care work uses time diaries to better understand whether inequalities in time burdens of women and men are a factor leading to chronic poverty, and constitute human rights violations for women. Understanding this imbalance will help ActionAid, its partners and rightsholders to propose alternative social policies to recognise and potentially reduce and redistribute women's disproportionate share of unpaid care work, both through facilitating better working conditions and through supporting change within the household.

While building wide engagement around an alternative vision of social protection that will reduce inequality, coalitions will be scoping opportunities for influencing duty-bearers. Influencing may involve advocacy activities at national or international levels. If a campaign is needed to harness the power of mass communications and mobilisation to leverage change, it might follow a sequenced approach. There could be a multi-year campaign focused on different issues each year - for example social protection policies for unemployed people one year; women in informal labour the next; people living with disabilities the following year (Thomson 2005). Any influencing to address poverty in NDSs needs to be underpinned by an analysis of inequality, power and rights and would be supported by developing an evidence base. All individual policies need to be articulated within a broad social protection framework forming part of such an alternative NDS.

At both local and national level, work would aim to build empowerment; ensuring rightsholders are engaged in the process with government. While the redistributive policies themselves are important, strong citizen monitoring, evaluation and feedback on policy implementation are required to ensure that policies continue to remain appropriate. This also helps build a relationship between citizens and the state, which may have as an outcome, the redistribution and then transformation of power. There would be solidarity building with local and national movements, and rightsholder involvement in campaigns, which might include mobilisations or participatory research.

\section{Conclusion}

A social protection framework based on, but broader than, the social minimum of cash transfers can be transformative, as it builds on the UN 'social floor' components of cash transfers and national social policies to include civil, political and economic rights. This means that rightsholders are better able to transform their lives following the intervention and ensure that in future crises they are no longer so vulnerable, as power has shifted. This framework will create change more effectively if it is central to a redistributive NDS. As part of this strategy, it has most potential for creating redistribution of power, reduction of inequality, and ensuring transformation of people's lives as linkages across sectors can be maximised.

In order to develop a context-specific social protection framework that will lead to more just outcomes within an 'alternative' NDS, a strong rights, power and inequality analysis is required at all levels. Unless inequality is the specific perspective and guiding focus, it will not decrease. At a local level, analysis can emerge from community discussions which can provide the space to further ensure accountability between citizens and state. 
An analysis of different inequalities will open new options for changes in power. Redistribution of power is important if all rights are to be fully realised. Achieving a full social protection agenda within a national development strategy will require working collectively across civil

\section{Notes}

1 This network of individuals and organisations across 25 African countries is committed to promoting and strengthening the social contract between states and citizens. A small secretariat supports the network to strengthen civil society engagement on social protection. For more information, see Africa Platform for Social Protection at: www.africacsp.org.

2 SEWA is an organisation and movement of poor, self-organised women workers in India, which seeks to ensure that women enjoy the benefits of full employment and self-reliance. It provides a range of services to support this aim (www.sewa.org).

3 The origin of the reinvigoration of the NDS was a United Nations General Assembly

\section{References}

BIG (Basic Income Grant) campaign, www.big.org.za/index.php?option= news\&Itemid $=2 \&$ topid $=0$ (accessed 24 July 2011)

Grosh, M.C.; del Ninno, C.; Tesliuc, E. and Ouerghi, A. (2008) For Protection and Promotion: The Design and Implementation of Effective Safety Nets, Washington DC: World Bank

IMF (International Monetary Fund) (2011) Fact Sheet: Poverty Reduction Strategy Papers, www.imf.org/external/np/exr/facts/ prsp.htm (accessed 24 July 2011)

Oportunidades programme, www.oportunidades.gob.mx/Portal/ (accessed 24 July 2011) society, bringing in different movements, including feminist movements. We should be agenda-setting and propositional, building on local and national analyses to develop practical redistributive development alternatives.

meeting in 2005, when leaders reaffirmed that each country has a primary responsibility for its own development and reiterated the importance of national policies and development strategies in achieving sustainable development.

4 For more information on ActionAid's NDS project, please contact the author, Kate Carroll. Note that in 2011, ActionAid's NDS project focuses on demonstrating how an alternative model of financing, using a redistributive tax system, can address inequalities in the social (education and health), productive (land and natural resource) sectors and the care economy.

Thomson, K. (2005) 'Campaign for Universal Social Protection', unpublished, London: ActionAid

Townsend, P. (2002) 'Poverty, Social Exclusion and Social Polarisation: The Need to Construct an International Welfare State,' in P. Townsend and D. Gordon (eds), World Poverty: New Policies to Defeat an Old Enemy, Bristol: The Policy Press

UN General Assembly (2005) 2005 World Summit Outcome, www.un.org/summit2005/ (accessed 24 July 2011)

UN, ILO, WHO (2010) Social Protection Floor Initiative Brochure, www.socialfloor.org (accessed 24 July 2011) 